May 2018

\title{
"The impact of increasing competition for non-contract parcels on postal prices and efficiency decisions"
}

Philippe De Donder, Frank Rodriguez and Soterios Soteri 


\section{The impact of increasing competition for non-contract parcels on postal prices and efficiency decisions ${ }^{1}$}

Philippe De Donder (IDEI, Toulouse School of Economics and Université du Québec à Montréal), Frank Rodriguez (Oxera Consulting LLP) and Soterios Soteri (Royal Mail Group)

\section{Introduction}

Letter volumes in countries with advanced postal networks have been in decline for many years and generating increasing pressure on postal universal service providers (USPs) to seek new revenue streams and increase efficiency to meet their regulatory and financial obligations. The increase in online shopping over the past decade and associated increased demand for parcels has provided postal USPs with a much needed boost to counter balance some of the challenges they are confronting. However, as the parcel market expands and evolves to meet changes in consumer patterns this brings forward new threats as well as opportunities for USPs. For example, while competition in some parts of the parcels market is already quite intense, especially the domestic bulk contract segments within some European countries, USPs face the threat of increasing competition in the single piece or noncontract parcel segment, especially from competitors that may potentially be operating at the margin of regulatory requirements. In particular, private individuals and small businesses, both of whom have traditionally sent parcels via USP Post Office outlets, are being offered an increasing range of options to send them via other parcel operators using alternative acceptance points, such as local convenience stores, retail outlets and locker banks.

The growth in on-line shopping therefore provides USPs with an opportunity to compete for higher parcel volumes but also poses a threat to elements of their traditional unique selling point via increasing competition to Post Office outlets. This paper develops and calibrates a theoretical model to assess the extent to which these two effects impact USPs' finances and the trade-offs they face between efficiency gains and pricing when operating within a regulatory framework. It builds on the model developed by De Donder et al. (2018), where a USP operates in several postal markets (single piece mail, bulk letters and bulk contract parcels) and faces direct competition in the latter two markets. The USP is assumed to maximize profits over two periods during which it is subject to regulatory constraints and changing market conditions. The current paper extends that model and the existing literature by introducing competition for non-contract parcels. More precisely, the singlepiece mail market is disaggregated into single piece letters (SPL), where the USP does not face any competition from other postal operators, and single piece parcels (SPP), where the USP faces increasing competition from private, profit-maximizing parcel operators. This added dimension increases the tensions being managed by the USP to achieve a feasible rate of efficiency and deliver a normal economic rate of return. Furthermore, increasing competition in the parcels market creates added uncertainty for the regulator in terms of setting price controls on the USP.

Section 2 outlines the model and in particular the extension to that developed by De Donder et al. (2018). Section 3 calibrates and applies the model to consider the tensions and trade-offs associated with the USP achieving different levels of efficiency under different degrees of competition in the SPP market. Section 4 reports sensitivities while Section 5 concludes and an appendix provides further details on the calibration of the model.

\footnotetext{
${ }^{1}$ The views expressed in this paper are those of the authors and do not necessarily reflect those of the organisations to which they are affiliated.
} 


\section{The Model}

\subsection{Operators and Markets}

The model developed in this paper extends the one presented in De Donder et al. (2018) (referred to as DRS henceforth) by modelling explicitly and separately the single-piece letters and single-piece parcels markets, which were previously merged under the heading "single-piece mail". In order for this paper to be self-contained, a full description of the analytical model is provided below.

There are two types of postal operators: a USP, denoted by $I$, and a set of competitors, denoted by $E$. There are five postal services: single-piece letters (SPL), bulk letters (BL), an access service for delivery of competitors' BL through the USP's network, single-piece parcels (SPP) and contract parcels (CP). In addition, there are two delivery areas in each postal market, urban (U) and rural (R). Each of the five postal markets is described sequentially, starting with the letters markets.

\section{$2.2 \quad$ Single-piece letters (SPL)}

The USP is subject to a USO to provide an SPL service of a given quality delivering at the same price to all addresses in both delivery areas. The USP enjoys a de facto monopoly on the SPL market as competitors do not find it profitable to offer an SPL service with these features.

The net utility that consumers in zone $i \in\{U, R\}$ obtain from consuming quantity $x$ of SPL at unit price $p$ is denoted by $u_{i}(x)-p x$. The demand function for SPL in zone $i$ is obtained by maximizing utility with respect to $x$, and is denoted by $x_{i}(p)$. Utility is quadratic in quantities, so that the demand function is linear and of the form $x_{i}(p)=\alpha-\beta p$. The unit variable cost for SPL is denoted by $c_{i}$. The contribution to USP profit of SPL in zone $i$ is then $\left(p-c_{i}\right) x_{i}(p)$. Note that the USP also faces a global fixed cost $F$ in order to meet the USO in all postal markets.

\section{$2.3 \quad$ Bulk letters $(B L)$}

The USP faces competition in the BL, SPP and CP markets. Competition in the former can be end-toend (E2E) or through access, with the USP selling both an E2E BL product to final consumers and an access service to competitors. In the case of access, each unit of competitors' BL requires one unit of access to the USP delivery network. The BL products offered by both operators are imperfect substitutes, whether the competitor uses access or bypasses the USP delivery network. Competitors then choose the cheapest way to deliver BL traffic (i.e., they offer an E2E product if the access charge is larger than their own delivery cost, and access the USP delivery network otherwise).

The net utility obtained by consumers in zone $i$ from consuming $\mathrm{BL}$ is $v_{i}\left(y_{i}^{I}, y_{i}^{E}\right)-q_{i}^{I} y_{i}^{I}-q_{i}^{E} y_{i}^{E}$, where $q_{i}^{j}$ denotes the consumer price operator $j \in\{I, E\}$ posts in zone $i$, and $y_{i}^{j}$ the quantity consumed of that good. The demand for goods in each zone is obtained by maximizing consumers' utility, and is denoted by $y_{i}^{I}\left(q_{i}^{I}, q_{i}^{E}\right)$ and $y_{i}^{E}\left(q_{i}^{I}, q_{i}^{E}\right)$. Note that both operators' prices influence demand for both goods, because the function $v_{i}$ is non separable in $y_{i}^{I}$ and $y_{i}^{E}$. The utility function $v_{i}($.$) is quadratic in quantities, so that BL demand functions are linear in$ prices. 
As for BL costs, $d_{i}^{j}$ denotes operator $j$ 's (constant) marginal delivery cost in zone $i$, and $b_{i}^{j}$ operator $j$ 's upstream constant unit cost in zone $i$. The competitors charge an exogenous mark-up $m_{L}^{E}$ over their marginal cost in both cases whose level reflects the intensity of competition on the market. If the access charge $a_{i}$ is smaller than the competitor's delivery cost $d_{i}^{E}$, the competitor chooses to access the USP's delivery network in zone $i$ and charges a price $q_{i}^{E}=\left(1+m_{L}^{E}\right)\left(a_{i}+b_{i}^{E}\right)$. If $a_{i}>d_{i}^{E}$ , the competitor prefers to offer an E2E product in zone $i$, whose price is $q_{i}^{E}=\left(1+m_{L}^{E}\right)\left(d_{i}^{E}+b_{i}^{E}\right)$.

The contribution to USP's profit of BL in zone $i$ is given by $\left(q_{i}^{I}-b_{i}^{I}-d_{i}^{I}\right) y_{i}^{I}\left(q_{i}^{I}, q_{i}^{E}\right)+\left(a_{i}-d_{i}^{I}\right) y_{i}^{E}\left(q_{i}^{I}, q_{i}^{E}\right)$, in the access case, and by $\left(q_{i}^{I}-b_{i}^{I}-d_{i}^{I}\right) y_{i}^{I}\left(q_{i}^{I}, q_{i}^{E}\right)$ in the bypass case.

\subsection{Contract Parcels (CP)}

Competition on the SPP and CP markets is of the E2E variety only. CP products sold by the USP and competitors are imperfect substitutes and there is no substitution between CP and SPP.

The net utility obtained by consumers in zone $i$ from consuming CP is $w_{i}\left(z_{i}^{I}, z_{i}^{E}\right)-s_{i}^{I} z_{i}^{I}-s_{i}^{E} z_{i}^{E}$, where $s_{i}^{j}$ denotes the consumer price operator $j \in\{I, E\}$ posts in zone $i$, and $z_{i}^{j}$ the quantity consumed of that good. The demand for goods in each zone is obtained by maximizing the consumers' utility, and is denoted by $z_{i}^{I}\left(s_{i}^{I}, s_{i}^{E}\right)$ and $z_{i}^{E}\left(s_{i}^{I}, s_{i}^{E}\right)$. Note that both operators' prices influence demand for both goods, because the function $w_{i}$ is non separable in $z_{i}^{I}$ and $z_{i}^{E}$. The utility function $w_{i}($.$) is quadratic in quantities, so that CP demand functions are linear in$ prices.

The constant unit variable cost for CP for operator $j$ in zone $i$ is denoted by $f_{i}^{j}$. There is no need to distinguish upstream and downstream costs as no access is provided for this good. Competitors charge an exogenous mark-up $m_{P}^{E}$ over their marginal costs: $s_{i}^{E}=\left(1+m_{P}^{E}\right) f_{i}^{E}$.

The contribution of CP to the USP's profit is $\left(s_{i}^{I}-f_{i}^{I}\right) z_{i}^{I}\left(s_{i}^{I}, s_{i}^{E}\right)$.

\section{$2.5 \quad$ Single-piece parcels (SPP)}

Competition in the SPP market is of the E2E variety, as in the CP market, but with two caveats. First, both the USP and competitors are assumed to post a uniform price in U and R. Second, consumers are assumed to bear a cost, beyond the price charged, to use the competitors' product. This cost reflects the fact that the density of contact points is, initially, lower for the competitors than for the USP. This user cost is borne by the sender of SPP and is additional to that incurred to use the USP's SPP service. In addition, the USP is meeting its USO obligations and, similar to SPL traffic, is obliged to provide a service of a given quality.

The amount of SPP sent to area $i=\{U, R\}$ by using the services of operator $j$ is denoted by $x_{S P, i}^{j}$. Operator $j$ charges the unit price $p_{S P}^{j}$ for this good and the unit variable cost in area $i$ for operator $j$ is $c_{S P, i}^{j}$. As for the (time and transportation) costs borne directly by senders, these are normalized to zero when using the USP's services, and denoted by $c u$ for the additional cost senders bear in using competitors' products. 
The net utility obtained by consumers in zone $i$ from consuming SPP is $w_{i}^{S}\left(x_{S P, i}^{I}, x_{S P, i}^{E}\right)-$ $p_{S P}^{I} x_{S P, i}^{I}-\left(p_{S P}^{E}+c u\right) x_{S P, i}^{E}$. The demand for goods in each zone is obtained by maximizing the consumers' utility, and is denoted by $x_{S P, i}^{I}\left(p_{S P}^{I}, p_{S P}^{E}+c u\right)$ and $x_{S P, i}^{E}\left(p_{S P}^{I}, p_{S P}^{E}+c u\right)$. The contribution of SPP to the USP's profit is $\left(p_{S P}^{I}-c_{S P, i}^{I}\right) x_{S P, i}^{I}\left(p_{S P}^{I}, p_{S P}^{E}+c u\right)$.

Entrants are assumed to post the mark-up $m_{S P}$ over their average variable costs when setting their uniform price:

$$
p_{S P}^{E}=\left(1+m_{S P}\right)\left[\frac{x_{S P, U}^{E}}{x_{S P, U}^{E}+x_{S P, R}^{E}} c_{S P, U}^{E}+\frac{x_{S P, R}^{E}}{x_{S P, U}^{E}+x_{S P, R}^{E}} c_{S P, R}^{E}\right]
$$

\subsection{Pricing and regulation}

The pricing behaviour of the competitors has been described in the four sub-sections above, and consists in posting specific mark-ups over variable costs. These mark-ups represent proxies for the degree of competition in each of the postal submarkets. The USP chooses the level of its prices $\left(p, q_{i}^{I}, s_{i}^{I}, p_{S P}^{I}\right)$ in order to maximize its profit, subject to the following constraints.

First, the regulator sets caps on the USP's SPL and the SPP prices, which contain the same mark-up $m_{S P}^{R}$ over variable costs:

$$
\begin{gathered}
p \leq\left(1+m_{S P}^{R}\right)\left[\frac{x_{U}}{x_{U}+x_{R}} c_{U}+\frac{x_{R}}{x_{U}+x_{R}} c_{R}\right], \\
p_{S P}^{I} \leq\left(1+m_{S P}^{R}\right)\left[\frac{x_{S P, U}^{I}}{x_{S P, U}^{I}+x_{S P, R}^{I}} c_{S P, U}^{I}+\frac{x_{S P, R}^{I}}{x_{S P, U}^{I}+x_{S P, R}^{I}} c_{S P, R}^{I}\right] .
\end{gathered}
$$

Second, the access charge in the BL market is set by the regulator such that $a_{i}=\left(1+m_{L}^{I}\right) d_{i}^{I}$, as applied in the numerical simulations in this paper, and passes a margin squeeze constraint: the difference between the USP's BL price an access charge, in any zone $i$, must be at least equal to the upstream costs of the USP in the zone: $q_{i}^{I}-a_{i} \geq b_{i}^{I}(1+\phi)$, where $\phi$ is the mark-up over upstream costs. Third, the difference between the (higher) SPL price $p$ and the USP's (lower) BL price $q_{i}^{I}$, in each zone, must be greater than the upstream preparation cost of the USP's BL final customers, $b^{p}: p-q_{i}^{I}>b^{p}, i \in\{U, R\}$.

Finally, note that the regulator sets the value of $m_{S P}^{R}$ so that the USP makes a normal rate of return (that is, it achieves zero economic profit and the margin made by selling all five types of services exactly covers the fixed cost $F$ of the USP). The regulator's primary objective is to ensure the USP is able to provide universal service on a continuing basis while allowing it to earn zero economic profit. In order to achieve this aim it is assumed that the regulator sets the SPL and SPP price caps using the same equi-proportionate mark-up on variable costs, $m_{S P}^{R}$, so that SPL and SPP consumers are safeguarded to the same extent against the possibility of excessive pricing by the USP.

The Appendix summarises the calibration values of the demand and cost parameters and these retain the same calibration assumptions as in DRS for all aspects of the model, except the new SPP and SPL markets. 


\subsection{Timing and decisions}

The model considers two periods, denoted by $\mathrm{P}_{1}$ and $\mathrm{P}_{2}$. All firms announce their prices for $\mathrm{P}_{1}$ at the beginning of $\mathrm{P}_{1}$. The regulator then announces details of the price constraints it will set during the next regulatory cycle, which is assumed to last five years, based on its assessment of prospects for mail demand and efficiency improvements. The regulator assesses the value of $e$, which is the yearly percentage reduction in (both variable and fixed) costs the USP could be expected to attain, and sets the values of $m_{S P}^{R}$ and the BL access price constraint for the second regulatory cycle. Reductions in costs may arise from improvements in productivity or lower wage costs or a mix of both factors. The value of $e$ is assumed to be obtained from a rigorous efficiency review process undertaken in $\mathrm{P}_{1}$ that yields a challenging yet achievable estimate in $\mathrm{P}_{2}$.

The USP then announces (in $\mathrm{P}_{1}$ ) efficiency targets to be achieved during the next regulatory cycle, but the value of $e$ it chooses need not equal that used by the regulator to set its price constraint.

Moving on to $\mathrm{P}_{2}$, it is assumed that the USP efficiency targets announced in $\mathrm{P}_{1}$ are achieved in $\mathrm{P}_{2}$ and, with a regulatory cycle of five years, USP costs decrease by $5 e$ by the end of $\mathrm{P}_{2}$. For simplicity, competitors' costs are assumed to be the same as in $\mathrm{P}_{1}$, such that $e$ can be interpreted as the amount by which the USP lowers its costs each year relative to competitors. At the same time, and independently from the variation in costs, market volumes of both operators are assumed to follow the same trend, with volumes varying by the same proportion for any given set of prices. This variation is given by the parameter $\lambda$ so that, for any given set of prices, mail volumes are $\lambda \%$ higher in $\mathrm{P}_{2}$ than in $\mathrm{P}_{1}{ }^{2}$ Letter volumes are assumed to face a negative trend ( $\lambda=\lambda^{L}<0$ due to e-substitution) while parcel volumes benefit from a positive trend $\left(\lambda=\lambda^{P}>0\right.$, due to e-commerce).

The USP then chooses prices for $\mathrm{P}_{2}$ to maximize profit in $\mathrm{P}_{2}$, subject to the price constraints set above, its costs (given its choice of $e$ ) and market demand during $\mathrm{P}_{2}$. Competitors post their prices for $\mathrm{P}_{2}$ simultaneously.

\section{Results from the Model: Single piece letters and parcels}

The operation of the model in the BL and CP markets adopts the same calibration assumptions as in DRS and hence the profit maximising prices and volumes for these segments are identical to their reported results ${ }^{3}$. Some of the key results in these markets are reported in Table 1 for ease of access. The discussion below instead focuses on the new dimension of the model, namely the disaggregation of single piece mail into SPL and SPP traffic streams. The calibration values for these sectors reflect broadly the characteristics of these markets in developed economies and further information is provided in the Appendix.

The first column of results contains the base case calibration in $\mathrm{P}_{1}$, where the regulator is assumed to set price caps for the USP's SPL and SPP services by some proportion above variable costs to allow the USP to earn a zero economic profit (that is, an accounting profit equal to 2.4bn€ to cover fixed costs and a normal rate of return) after taking into account the impact of competition in the BL, CP and SPP markets. With respect to the SPP market, it is assumed that parcel competitors to the USP compete for traffic by offering prices at a mark-up of 3\% over their variable costs for a more restrictive service in terms of sender acceptance points relative to the USP. This latter point is captured in the model by $c u$ (the additional cost borne by the sender when using a competitor SPP

\footnotetext{
${ }^{2}$ So that, for instance, the demand function for SPL in $\mathrm{P}_{2}$ becomes $x_{i}(p)=(1+\lambda)(\alpha-\beta p)$.

${ }^{3}$ In particular, see the results for the USP and Competitor BL and CP volumes and prices contained in DRS Table 1, under the column headings "P1 no strike" and "P2 with 2\% efficiency and no strike". In both these cases competitors offer BL through access to the USP's delivery network (rather than bypass) and the prices set by the USP satisfy the margin squeeze condition set by the regulator.
} 
service instead of the USP) and set equal to 0.6 in $\mathrm{P}_{1}$. At the base case calibration values, the USP's SPL price is $1.105 €$ which is equal to the maximum price allowed by the regulatory cap. However, due to the competitive nature of the SPP market the USP's price of $5.636 €$ is below the price cap of $6.63 €$ and competitor price of $6.00 €$ resulting in competitors capturing $21 \%$ of total SPP market volumes ${ }^{4}$.

Letter volumes are declining by significant amounts in most developed countries while parcel volumes are growing rapidly. In the numerical simulation, similar to DRS, it is assumed that the regulator expects letter volumes in $\mathrm{P}_{2}$ to decline by $20 \%$ over a five year period relative to $\mathrm{P}_{1}$ and parcel volumes to increase by $20 \%$ and, in the light of these assumptions, sets price controls for the USP in $\mathrm{P}_{1}$ that will allow it to earn a normal rate of profit in $\mathrm{P}_{2}$ if it achieves efficiency improvements of $2 \%$ per annum and avoids industrial action. The regulator monitors evolving trends in the parcels market and takes account of increasing competition in the SPP market where it expects competitors to expand their number of collection points making it easier for senders of low volume parcels to do business with them. This is captured in the model by a decline in $c u$ from 0.6 in $\mathrm{P}_{1}$ to zero in $\mathrm{P}_{2}$, a value which the market could be expected to move towards over the longer term. The second column of results in Table 1contains the $\mathrm{P}_{2}$ profit maximising prices and volumes for the USP and competitors if the regulator's assumptions made in $\mathrm{P}_{1}$ for $\mathrm{P}_{2}$ turn out to be correct. In this specific case, while increased competition in the SPP market results in a higher market share for competitors (from 20.8\% in $\mathrm{P}_{1}$ to $28.8 \%$ in $\mathrm{P}_{2}$ ) the increase in the demand for parcels and improvement in USP efficiency levels allow the regulator to reduce the letter and parcel price caps in $\mathrm{P}_{2}$ so that the USP can still earn a normal rate of return (that is, an economic profit of zero). Similar to $\mathrm{P}_{1}$, the impact of competition in the SPP market results in the USP's profit maximising price being lower than the SPP price cap (of $5.557 €)$.

However, the future rarely turns out to be exactly as expected. The results reported in the third column refer to the situation where competition in the SPP market in $\mathrm{P}_{2}$ is somewhat higher than expected in $\mathrm{P}_{1}$, due to say parcel competitor access points to send SPP traffic exceeding those of the USP, and is modelled by reducing $c u^{5}$ from zero to -1 in $\mathrm{P}_{2}$. The model results are directionally intuitive, such that when the USP faces higher levels of competition in the SPP market its profit maximising prices decline (from 5.201 to 4.674), parcel competitors gain market share (from $28.8 \%$ to $45.3 \%$ ) and total market volumes increase (from $243 \mathrm{~m}$ to $261 \mathrm{~m}$ items). In this scenario, despite achieving its regulatory efficiency target of $2 \%$ per annum, the USP makes an economic loss of $166 \mathrm{~m} €$ in $\mathrm{P}_{2}$ as it is prevented from raising SPL prices by the regulatory price cap which is binding (equal to 0.926 ).

The final column of results in Table 1 refers to the situation where the USP is assumed to increase efficiency by $3 \%$ per annum without incurring any industrial action, which is $1 \%$ higher per year than the assumption adopted by the regulator to inform the price control it set in $\mathrm{P}_{1}$. In this case, the USP's costs are lower which increases the contribution to profit from all segments of mail and also leads to lower profit maximising prices for its SPP traffic (declining from 5.201 to 5.141) with parcel competitors losing market share in this segment of the market (from $28.8 \%$ to $27.4 \%$ ). The end

\footnotetext{
${ }^{4}$ If the regulator had tried to set a lower cap on the SPL price so that caps on SPL and SPP had been equal and binding, it would have reduced the contribution the USP would be able to raise from SPL without changing that from SPP. A cap set at the profit-maximizing price for the USP's SPP service would only produce the same level of contribution for it in the SPP market but such an outcome would lead to the USP making a negative profit overall due to the reduced contribution at that lower cap from SPL.

${ }^{5}$ Amending the competitor SPP user cost parameter is the most direct way to model the impact of increasing competition in the model. The directional effects of this change would be similar to shifting the parcel competitor switching function such that competitors were more competitive at all price points which might be due to say an upward shift in the quality of services provided by competitors at any given price.
} 
result of the USP's higher than expected efficiency performance in $\mathrm{P}_{2}$ is a positive economic profit of $215 \mathrm{~m} €$.

Table 1. Prices, volumes and economic profit under different conditions of competition and efficiency in the single piece parcel market

\begin{tabular}{|c|c|c|c|c|}
\hline & $\begin{array}{l}\mathrm{P}_{1} \text { with } \\
c u=0.6\end{array}$ & $\begin{array}{l}\mathrm{P}_{2} \text { with } c u=0 \\
\& \mathrm{e}=2 \% \text { p.a. }\end{array}$ & $\begin{array}{l}\mathrm{P}_{2} \text { with } c u=-1 \\
\& \mathrm{e}=2 \% \text { p.a. }\end{array}$ & $\begin{array}{l}\text { P2 with } c u=0 \\
\& \mathrm{e}=3 \% \text { p.a. }\end{array}$ \\
\hline \multicolumn{5}{|l|}{ Prices, euro } \\
\hline USP SPL & 1.105 & 0.926 & 0.926 & 0.926 \\
\hline USP SPP & 5.636 & 5.201 & 4.674 & 5.141 \\
\hline Parcel competitor SPP & 6.000 & 6.000 & 6.000 & 6.000 \\
\hline \multicolumn{5}{|c|}{ All other prices as per DRS and not repeated here } \\
\hline Volumes, billions of items & & & & \\
\hline $\begin{array}{l}\text { Total across all markets } \\
\text { (SPL,SPP,BL,CP) }\end{array}$ & 12.766 & 11.485 & 11.503 & 11.558 \\
\hline USP SPL & 1.581 & 1.336 & 1.336 & 1.336 \\
\hline USP SPP & 0.153 & 0.173 & 0.143 & 0.176 \\
\hline Parcel competitor SPP (\% market & 0.040 & 0.070 & 0.118 & 0.066 \\
\hline share in brackets) & $(20.8 \%)$ & $(28.8 \%)$ & $(45.3 \%)$ & $(27.4 \%)$ \\
\hline Total SPP & 0.193 & 0.243 & 0.261 & 0.243 \\
\hline All other volumes (BL, CP jointly) & 10.992 & 9.905 & 9.905 & 9.979 \\
\hline $\begin{array}{l}\text { USP economic profit net of fixed } \\
\text { costs, billions of euro }\end{array}$ & 0 & 0 & -0.166 & 0.215 \\
\hline $\begin{array}{l}\text { USP contribution to profit, } \\
\text { of which: }\end{array}$ & 2.400 & 2.160 & 1.994 & 2.255 \\
\hline USP contribution from SPL & 1.114 & 0.756 & 0.756 & 0.783 \\
\hline USP contribution from SPP & 0.497 & 0.526 & 0.360 & 0.547 \\
\hline USP contribution from BL, CP & 0.790 & 0.878 & 0.878 & 0.925 \\
\hline Net consumer surplus (SPL) & 2.620 & 2.329 & 2.329 & 2.329 \\
\hline
\end{tabular}

Note that P1 and P2 refer to the last year of a five year regulatory cycle.

The relationship between SPL and SPP price caps and increasing levels of competition in the SPP market in $\mathrm{P}_{2}$ is examined further in Figure 1 assuming both $\mathrm{BL}$ and $\mathrm{CP}$ markets remain as in the base. This plots the level of the SPP price cap required to generate zero economic profit for different degrees of competition in the SPP market (represented in the model by the sender user cost parameter, $\mathrm{cu}$ ) and also plots the USP's SPL price cap and profit-maximising SPP price after normalising them to equal unity in the $\mathrm{P}_{2}$ base case where $c u$ equals zero. Table 1 reported these prices for just two states of competition in the SPP market (where $c u$ was equal to 0 and -1). The schedules for both the SPL and SPP price caps are approximately linear ${ }^{6}$ and slope downwards to reflect the need for higher prices to counter-balance the increasing loss in contribution from SPP traffic at higher levels of competition in this segment of the market.

The profit maximising prices set by the USP in Figure 1 result in the SPL price cap schedule always acting as a binding constraint in our calibrated model while the SPP price cap does not. In the latter case, where competition in the SPP market is low the parcels price cap is binding but when competition increases beyond a certain point the profit maximising price charged by the USP falls below the price cap. With our calibration, this switching occurs when the user cost value is below about 0.3 and, in general, the USP's SPP price is the lower of the regulated price cap and its profitmaximising price. An important point to note from this analysis is that the greater is the intensity of

\footnotetext{
${ }^{6}$ This is due, among others, to assuming that the regulator adopts an equi-proportional mark-up rule in setting caps to derive a zero economic profit.
} 
competition in the SPP market, the lower are both the profit-maximising SPP price and the contribution of the SPP market to the USP's profit. This in turn requires the regulator to raise the SPL price cap to allow the USP to earn a zero economic profit. For example, with regards to the $166 \mathrm{~m} €$ loss in profit reported in Table 1 (penultimate column), due to competition in the SPP market in $\mathrm{P}_{2}$ being greater than the regulator expected in $\mathrm{P}_{1}$, this loss could potentially be offset by raising the SPL price cap from 0.926 to 1.085 in $\mathrm{P}_{2}$.

Figure 1. USP prices in $P_{2}$ at break-even under different degrees of competition in the SPP market $(e=2 \%)$

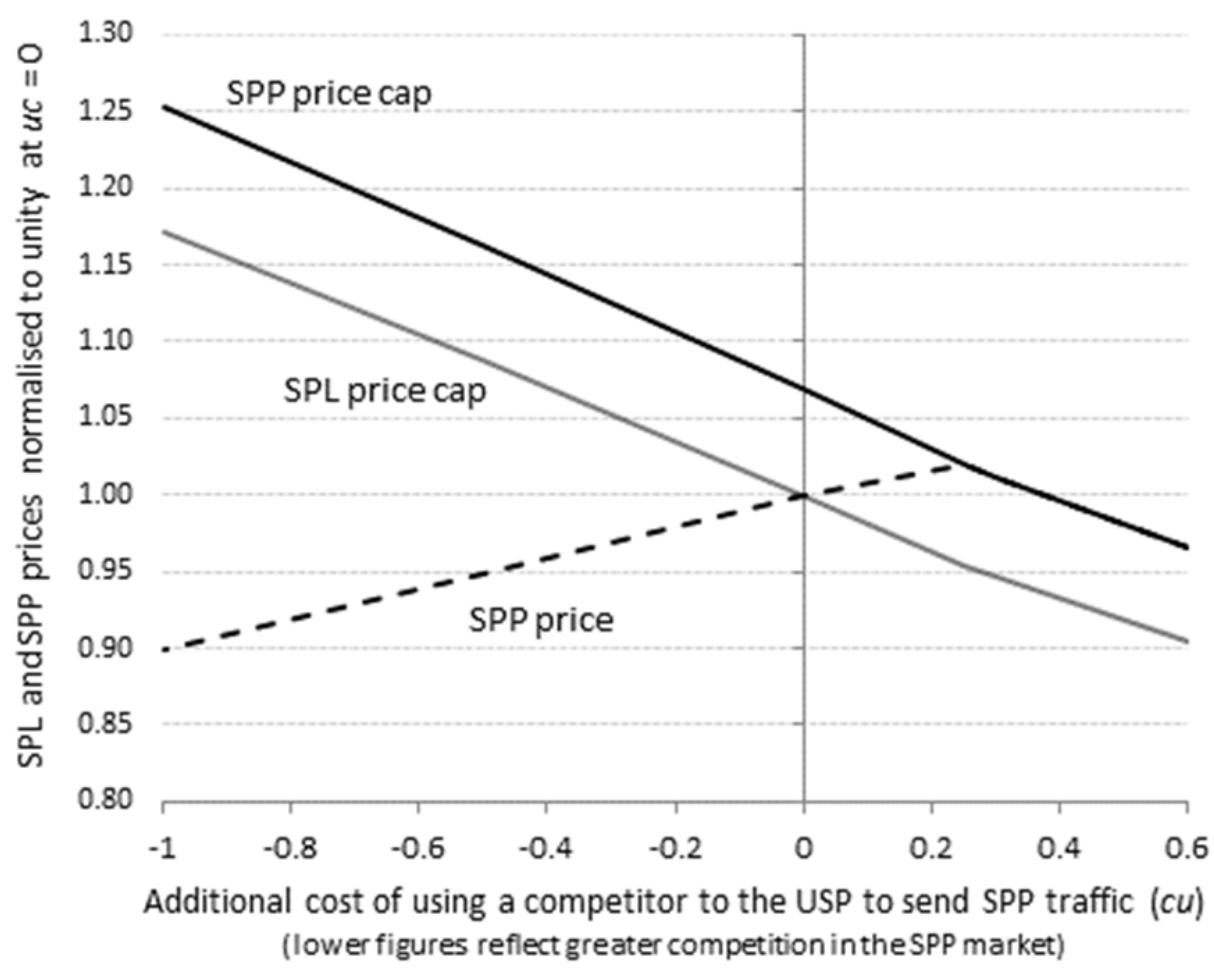

\section{Sensitivities}

This section considers the impact of additional sensitivities to our calibrated model assumptions. In each case, the sensitivity impact refers to a change in the USP's economic profit in $\mathrm{P}_{2}$ relative to the base case reported in Table 1 (second column of results).The sensitivities undertaken focus on four different types of unexpected external shocks that could impact the USPs financial position and they are reported in Table 2. The first three assume only one of the calibrated model assumptions change while all others remain the same as in the base case. However, in the fourth sensitivity the USP is allowed the option to respond to a negative shock by adjusting its efficiency target to try and protect its financial position but in doing so raises the risk of industrial action taking place.

The first two sensitivities examine the impact of unexpected declines in mail volumes due to external factors. In the first, letter volumes are assumed to be $10 \%$ lower in $\mathrm{P}_{2}$ (and so $30 \%$ below their level in $\mathrm{P}_{1}$ ) due to, say, increasing e-substitution. In this sensitivity, prices and volumes remain unchanged in all segments of the parcels market, as do bulk letter prices. Furthermore, since the SPL price in the base case is at the maximum allowable under the price cap set for $\mathrm{P}_{2}$ in $\mathrm{P}_{1}$ the USP is prevented from raising SPL prices to offset the impact of lower letter demand and this results in a loss of economic profit of $134 \mathrm{~m} €$. Note that if the regulator had expected letter volumes to decline by $30 \%$ rather than $20 \%$, then given the price inelastic nature of SPL traffic it would have been necessary to 
set a higher letter price cap to allow the USP to breakeven, but as a result senders of SPL mail would suffer a loss of net consumer surplus due to the higher SPL price. The second sensitivity assumes parcel volumes unexpectedly outturn at $10 \%$ higher in $\mathrm{P}_{2}$ as opposed to the $20 \%$ increase assumed by the USP and regulator. This has no effect on the SPL or BL markets in our model. Furthermore, the downward shift in demand for parcels does not impact profit-maximising prices for either of the SPP or CP segments. However, the decline in parcel volumes results in a lower contribution to profit compared to the base case, resulting in a 91m€ loss in $\mathrm{P}_{2}$. Both these sensitivities indicate that uncertainty associated with the demand for mail can have a substantial impact on the USP's financial position. In terms of addressing such challenges there is no simple regulatory solution, although aspects of setting price caps in an environment where a range of factors might impact on the appropriate level of caps have been explored by Brennan and Crew (2016).

The third sensitivity assumes that stricter labour legislation, or adherence to existing legislation, results in parcel competitor costs being $5 \%$ higher in $\mathrm{P}_{2}$ than the USP or regulator anticipated when the price cap was set in $\mathrm{P}_{1}$. Higher parcel competitor costs are assumed to feed directly through to their prices, as they are simply a mark-up over costs. In this environment, the USP's profitmaximising solution is to simultaneously raise prices a little and win more parcel volumes, both of which contribute to increasing profit by $163 \mathrm{~m} €$ in $\mathrm{P}_{2}$ relative to the base case. ${ }^{7}$

In the fourth sensitivity it is assumed that competition in the SPP market is higher than the regulator expected and, as in Section 3, this is examined by lowering the SPP user cost value to - 1 . In the absence of any response from the USP and no strike action taking place, its economic profit would decline by 166m€ (see Table 1, third column of results). However, financial pressures, especially for privatised USPs, are likely to incentivise them to respond and implement operational efficiency initiatives faster than they would otherwise have targeted. In such a scenario the USP would be forced to balance the competing pressures of incurring an economic loss and offsetting this by pressing for higher efficiency gains that could lead to costly strike action taking place. For example, the results

Table 2: Sensitivities to assumptions and USP changes to economic profit in $\mathrm{P}_{2}$ relative to the base case with sender user cost equal to zero

\begin{tabular}{|c|c|c|c|}
\hline \multicolumn{2}{|r|}{ Changes in assumptions relative to base case } & \multicolumn{2}{|c|}{$\underline{\text { Change in economic profit in } \mathrm{P}_{2}} \underline{\underline{ }}$, bns $^{\mathrm{b}}$} \\
\hline 1 & Letter volumes lower by $10 \%$ in $\mathrm{P}_{2}$ a & \multicolumn{2}{|c|}{-0.134} \\
\hline 2 & Parcel volumes lower by $10 \%$ in $\mathrm{P} 2{ }^{\mathrm{a}}$ & \multicolumn{2}{|c|}{-0.091} \\
\hline 3 & Parcel competitor costs increase by $5 \%$ in $\mathrm{P}_{2}$ & \multicolumn{2}{|c|}{0.163} \\
\hline 4 & \multicolumn{3}{|c|}{$\begin{array}{c}\text { Competition in the SPP market is more intensive, such that } c u=-1 \text {, and the USP responds by: } \\
\text { No strike case }\end{array}$} \\
\hline a & $\begin{array}{l}\text { USP raises its efficiency target to } 2.8 \% \text { and increases the risk of } \\
\text { industrial action occurring }{ }^{c}\end{array}$ & 0.003 & -0.460 \\
\hline $\mathrm{b}$ & $\begin{array}{l}\text { USP maintains its original } 2 \% \text { efficiency target and does not } \\
\text { increase the risk of industrial action occurring }{ }^{c}\end{array}$ & -0.166 & -0.516 \\
\hline
\end{tabular}

Notes:

${ }^{a}$ Changes affecting volumes are approximately symmetric in the opposite direction.

${ }^{\mathrm{b}}$ Figures refer to $\mathrm{P}_{2}$ which is the final year of a five year regulatory cycle and are not comparable with the results in Table 2 of DRS which contain present value estimates covering six years (the final year of the previous regulatory cycle, $\mathrm{P}_{1}$, and the five years of the following cycle to $\mathrm{P}_{2}$ ).

${ }^{\mathrm{c}}$ The assumptions underpinning the cost of a strike occurring in $\mathrm{P}_{2}$ are similar to those contained in DRS, see page 244. However, note that the strike in this sensitivity occurs in $P_{2}$ in contrast to the assumptions contained in DRS which assume it takes place in $\mathrm{P}_{1}$.

\footnotetext{
${ }^{7}$ Note that the increase in parcel prices in the SPP market occurs as a result of the price cap not binding in our calibrated model. If it were to this would constrain the USP's price and only volumes would adjust.
} 
reported in sensitivity 4a suggest that if the USP could achieve a higher level of efficiency of say $2.8 \%$, compared to the base case of $2 \%$, and avoid a strike in $\mathrm{P}_{2}$ it could avoid a financial loss and achieve a zero economic profit. However, the results also show that if a strike were to occur and the assumptions concerning the loss in USP traffic following a strike in $\mathrm{P}_{2}$ were similar to those contained in DRS, as described in the Appendix, then this would lead to a substantial loss in $\mathrm{P}_{2}$ of $460 \mathrm{~m} €$. Note that, as the results reported in sensitivity $4 \mathrm{~b}$ indicate, this loss would be somewhat lower than the $516 \mathrm{~m} €$ loss the USP would suffer if it maintained its original efficiency target of $2 \%$ pa, although it is likely that the risk of a strike would be higher when targeting efficiency gains of $2.8 \%$ pa.

\section{Conclusions}

The increase in on-line shopping and demand for parcels has provided postal USPs with a much needed boost to counter balance some of the challenges they are confronting with respect to declining letter volumes. However, as parcel markets have expanded and evolved to meet changes in consumer patterns it brings forward new threats as well as opportunities for USPs. In particular, while competition is intense in some domestic bulk contract parcel markets in Europe, USPs face the threat of increasing competition for single piece (or non-contract) parcel traffic, especially from competitors that may potentially be operating at the margin of regulatory requirements.

This paper extends the model developed by De Donder et al. (2018) to examine the impact of increasing competition in the single piece parcel (SPP) market. The model structure and assumptions consist of a number of key elements. First letter volumes are in long term decline due to esubstitution. Second the USP is required to meet a pre-specified USO but competitors are not required to do so. Third the USP is subject to price controls set by a regulator. Fourth, fixed costs are inherent in meeting the USO.

Similar to De Donder et al., the model assumes that the regulator sets a price control structure that requires the USP to achieve a specific rate of efficiency if a number of market conditions hold during the price control period for the USP to earn a zero economic profit. The model assumes that the USP maximises profit subject to the regulatory constraints and the external environment it operates within, which may differ from those assumed by the regulator when setting price caps for single piece letters (SPL) and SPP. However, the future rarely turns out as expected and the paper explores the impact of a number of unexpected events using sensitivity analysis to provide some important insights. In particular, these show that if competition in the SPP market turns out to be greater than expected at the time of setting regulatory price caps this could potentially lead the USP to incur a significant financial cost if it was unable to sufficiently increase the pace of its operational efficiency program to counterbalance this or if, as a result of trying to achieve these efficiency savings, it triggered costly strike action.

Our results also show that increasing competition in the SPP market implies higher price caps be set for SPL and possibly also for SPP although the latter may not always be binding if there is sufficient competition in the SPP market.

The paper models a number of other sensitivities resulting from unexpected shocks, including lower levels of demand for letters and parcels, higher parcel competitor costs resulting from changes in labour regulations (or stricter adherence to existing legislation) and higher efficiency levels while avoiding strike action. The direction of movement in the USP's financial position resulting from these sensitivities is consistent with what economic theory would expect. Furthermore, to a first approximation the individual sensitivities are symmetric in terms of their direction of movement and broadly additive which, to some extent, allows these to be combined numerically.

A key point to note from these sensitivities is that a range of plausible external shocks could have a substantial impact on the USP's financial position, even if it were to deliver its efficiency 
targets, and that fixed pre-determined single piece price caps could impose a significant constraint on the USP's ability to achieve a normal rate of economic profit. Aspects of setting price caps in an environment where a range of factors might impact on the appropriate level of caps have been addressed in recent literature (Brennan and Crew, 2016). The current paper has highlighted the importance of allowing for a number of such factors, and the uncertainty inherent in many of them, in setting a framework which is able to underpin the financial sustainability of universal service.

\section{Appendix}

\section{1) Calibration for simulations}

(A) Demand. For SPL, BL, SPP and CP markets, when the retail price of the good considered is the same in both zones, the urban zone represents $80 \%$ of total volumes, and the rural zone $20 \%$.

SPL market: at a price of $p=0.667 €$, total volume of $1.8 \mathrm{bn}$ items, and direct price elasticity of demand of -0.2 .

SPP market: hypothetical monopoly setting: at a price of $p_{S P}^{I}=4$, demand price elasticity of -0.2 (in both zones), and total volume of 0.2 billion items. With competition, displacement ratio $\left[\partial x_{S P, i}^{I}\left(p_{S P}^{I}, p_{S P}^{E}+c u\right) / \partial p_{S P}^{E}\right] /\left[\partial x_{S P, i}^{E}\left(p_{S P}^{I}, p_{S P}^{E}+c u\right) / \partial p_{S P}^{E}\right]=0.75$. USP market share of $70 \%$ when $p_{S P}^{I}=p_{S P}^{E}=6$ and cu=0.6 and of $90 \%$ when $p_{S P}^{I}=6, p_{S P}^{E}=6.6$ and $\mathrm{cu}=0.6$.

BL market: hypothetical monopoly setting: at a price of 0.4 , demand price elasticity of -0.4 (in both zones), and total volume of 7.5 billion items. With competition, displacement ratio

- $\left[\partial y_{i}^{I}\left(q_{i}^{I}, q_{I}^{E}\right) / \partial q_{i}^{E}\right] /\left[\partial y_{i}^{E}\left(q_{i}^{I}, q_{I}^{E}\right) / \partial q_{i}^{E}\right]$ of 0.9. Market share of $25 \%$ for competitors when $q_{i}^{I}=q_{i}^{E}=0.4$ and of $50 \%$ when $q_{i}^{I}=0.4$ and $q_{i}^{E}=0.36$.

CP market: assuming that the USP price in the urban (resp., rural) area is 1.9 (resp., 2.4) and that competitors are $10 \%$ more expensive than the USP, demands are calibrated so that (i) the displacement ratio is 0.75 , (ii) the demand price elasticity is - 0.2 , (iii) the USP volume is 0.4 (resp., 0.1 ), (iv) the USP's market share is $35 \%$. For equal USP and competitors' prices, the USP's market share is $10 \%$.

\section{(B) Costs (in $\mathbf{P}_{1}$ ).}

SPL market: unit variable cost $c_{i}$ of 0.38 in urban area $(i=U)$ and 0.48 in rural area $(i=R)$.

SPP market: unit variable costs: $c_{S P, U}^{I}=2.28, c_{S P, R}^{I}=2.88, c_{S P, U}^{E}=c_{S P, R}^{E}=5.83$.

BL market: same upstream variable cost in both zones for both operators: $b_{U}^{I}=b_{U}^{E}=b_{R}^{I}=b_{R}^{E}=0.02$.

Upstream preparation cost of the USP's BL final customers: $b^{p}=0.15$. USP's downstream cost: $d_{U}^{I}$ $=0.19$ and $d_{R}^{I}=0.34$. Competitors' downstream cost: $d_{U}^{E}=0.28$ and $d_{R}^{E}=0.74$.

CP market: unit variable costs: $f_{U}^{I}=1.14, f_{R}^{I}=1.44, f_{U}^{E}=2, f_{R}^{E}=2.6$.

USP: fixed cost of $F=2.4$. All (variable and fixed) USP costs decrease by $5 \mathrm{e} \%$ between $\mathrm{P}_{1}$ and $\mathrm{P}_{2}$.

(C) Mark-ups. USP mark-up for access charge set by the regulator: $m_{L}^{I}=0.1$ and $\phi=2 / 3$.

Competitors' mark-up in BL market: $m_{L}^{E}=0.02$; in SPP market: $m_{S P}=0.03$; and in CP market: $m_{P}^{E}=0.03$.

(D) Exogenous variations in volumes. Exogenous volume trend between $\mathrm{P}_{1}$ and $\mathrm{P}_{2}$ for letters are $\lambda^{L}=-0.2$ and for parcels $\lambda^{P}=0.2$. 
If a strike occurs in $\mathrm{P}_{2}$ (see sensitivities $4 \mathrm{a}$ and $4 \mathrm{~b}$ in Table 2), USP volumes are assumed to decrease by a fraction $\gamma^{L}(e)$ in the (single-piece and bulk) letter markets, and by $\gamma^{P}(e)$ in the (single-piece and contract) parcels markets. The functions $\gamma^{L}$ and $\gamma^{P}$ are both increasing in $e$, as the announcement of a larger decrease in costs is likely to result in more severe industrial action. In particular, the volume loss by the USP in the case of a strike in $\mathrm{P}_{2}$ as a proportion of the USP's pre-strike volume is equal to $\gamma^{L}(e)=0.04+4 e$ and $\gamma^{P}(e)=0.08+8 e$, where $e$ is expressed as a proportion (for example, $e=$ $2 \%$ as $e=0.02$ ). Competitors' volumes are similarly affected in the BL market (since the USP delivers these volumes on the competitors' behalf, at equilibrium). As for the (single-piece and contract) parcels markets, a fraction $\beta=0.8$ of the volumes assumed to be lost by the USP due to the strike is diverted towards the competitors. So, for instance, in the CP market, USP demand when a strike occurs in $\mathrm{P}_{2}$ becomes $\left(1+\lambda^{P}\right)\left(1-\gamma^{P}(e)\right) z_{i}^{I}\left(s_{i}^{I}, s_{i}^{E}\right)$ while the competitors' demand becomes $\left(1+\lambda^{P}\right)\left(z_{i}^{E}\left(s_{i}^{I}, s_{i}^{E}\right)+\beta \gamma^{P}(e) z_{i}^{I}\left(s_{i}^{I}, s_{i}^{E}\right)\right)$

\section{REFERENCES}

Brennan T.J. and Crew, M.A. (2016). Price Cap Regulation and Declining Demand. In M.A. Crew and T.J. Brennan (Eds), The Future of the Postal Sector in a Digital World, Springer.

De Donder, P., Rodriguez, F. and Soteri, S. (2018). Pricing and Efficiency Decisions for Letter and Parcel Markets when Industrial Relations Matter. In T.J. Brennan\& P. L. Parcu (Eds), The Contribution of the Postal and Delivery Sector, Springer. 